\title{
Incorporation of $\mathrm{ZnO}$ nanoparticles in polymeric matrices as $\mathrm{UV}$ protector
}

\section{Incorporación de nanopartículas de $\mathrm{ZnO}$ en matrices poliméricas como protector de UV}

MONTERO-GUZMAN, Erika†, GALINDO, R. and FUENTES-RAMIREZ, R.

Universidad de Guanajuato, Department of Natural And Exact Sciences, Mexico.

ID $1^{\text {st }}$ Author: Erica, Montero-Guzman / ORC ID: 0000-0002-2760-271X, CVU CONACYT ID: 887231

ID $1^{\text {st }}$ Coauthor: $R$., Galindo / ORC ID: 0000-0002-3612-1555, SNI CONACYT ID: 223987

ID $2^{\text {nd }}$ Coauthor: R., Fuentes-Ramirez / ORC ID: 0000-0003-0520-3387, SNI CONACYT ID: 202669

DOI: $10.35429 /$ JTI.2020.20.7.7.12

Received January 10, 2020; Accepted June 29, 2020

\begin{abstract}
At present there is great interest in the development of new nanomaterials that can be applied in different areas of study such as chemistry, physics, medicine, among others. In many polymeric materials, especially when used in coatings exposed to sunlight, they cause photolysis and photooxidation reactions, leading to the degradation of their physical-mechanical, optical and other properties. Therefore, the need to look for new materials capable of resisting radiation for prolonged periods, while retaining its original characteristics, such as hue and brightness, is imperative. Zinc oxide nanoparticles have attracted great interest in this aspect as they are used in most commercial sunscreens that use inorganic pigments, for their ability to adsorb ultraviolet rays. In the present work, the incorporation of the $\mathrm{Np}-\mathrm{ZnO}$ in situ during the polymerization by the emulsion process of butyl acrylate was carried out. $\mathrm{ZnO}$ nanoparticles are incorporated into butyl polyacrylate in different concentrations of $0.3 \%$, $0.5 \%$, and $1 \% \mathrm{~W}$, in which it is observed that at $1 \%$ there is greater agglomeration and in the others it does not affect the morphology of our polymer.
\end{abstract}

UV protection, Polymerization, Nanocomposites, Emulsion, Zinc oxide nanoparticles, Butyl polyacrylate, Free radicals

\begin{abstract}
Resumen
En la actualidad, existe un gran interés en el desarrollo de nuevos nanomateriales que puedan aplicarse en diferentes áreas de estudio, como la química, la física, la medicina, entre otras. En muchos materiales poliméricos, especialmente cuando se usan en recubrimientos expuestos a la luz solar, causan reacciones de fotólisis y fotooxidación, lo que conduce a la degradación de sus propiedades físico-mecánicas, ópticas y de otro tipo. Por lo tanto, la necesidad de buscar nuevos materiales capaces de resistir la radiación durante períodos prolongados, manteniendo sus características originales, como el tono y el brillo, es imprescindible. Las nanopartículas de óxido de zinc han atraído un gran interés en este aspecto, ya que se usan en la mayoría de los protectores solares comerciales que usan pigmentos inorgánicos, por su capacidad de adsorber los rayos ultravioletas. En el presente trabajo, se llevó a cabo la incorporación del Np$\mathrm{ZnO}$ in situ durante la polimerización mediante el proceso de emulsión de acrilato de butilo. Las nanopartículas de $\mathrm{ZnO}$ se incorporan al poliacrilato de butilo en diferentes concentraciones de $0.3 \%, 0.5 \%$ y $1 \% \mathrm{~W}$, en las cuales se observa que al $1 \%$ hay una mayor aglomeración y en las demás no afecta la morfología del polímero.
\end{abstract}

Protección UV, Polimerización, Nanocompuesto, Emulsión, Óxido de zinc, Nanopartículas, Poliacrilato de butilo, Radicales libres

\footnotetext{
Citation: MONTERO-GUZMAN, Erika, GALINDO, R. and FUENTES-RAMIREZ, R. Incorporation of ZnO nanoparticles in polymeric matrices as UV protector. Journal of Technology and Innovation. 2020. 7-20:7-12.
}

\footnotetext{
$\dagger$ Researcher contributing as first author.
} 


\section{Introduction}

After World War II, emulsion polymerization became a process widely used at the industrial level due to the ease of producing materials from vinyl monomers, these contain in their molecular structure a double bond $\mathrm{C}=\mathrm{C}\left(-\mathrm{CH}=\mathrm{CH}_{2}\right)[1]$.

Due to the ease of reaction control by the emulsion process, it is possible to simultaneously obtain high molecular weights of the desired polymer, as well as high reaction rates and excellent heat transfer in higher volume reactors, in contrast to other processes of polymerization, such as mass, solution and suspension $[2,3]$.

The polymers that are used as coatings in plastics, metals, wood, crystals among others and that are exposed to the Sun, suffer damage over time. This is largely caused by ultraviolet (UV) radiation, causing them to have great wear and loss of their original properties. That said, in the present research project a polymeric material is sought that has a better resistance to UV radiation, in order to increase the useful life of the substrates to be protected [4].

The rise of nanotechnology has brought with it the development of many technologies, capable of improving aspects such as the durability or comfort of things, thus several industries have benefited.

\section{Overall objective}

To evaluate the effect produced by the incorporation of $\mathrm{ZnO}$ nanoparticles (in situ process) from the polymerization of butyl acrylate by the emulsion process.

\section{Specific objectives}

- Synthesize polymers of butyl acrylate under the emulsion process via free radicals.

- Analyze the emulsion process based on the variables that affect it such as temperature, rpm, concentration of the continuous and dispersed phase.

- Incorporate zinc oxide NP (in situ) into the polymer matrix for UV protection.

- Perform mechanical tests of materials obtained on different surfaces.

\section{Materials and methods}

Reagents

The reagents used for the investigation are butyl acrylate (BA), potassium persulfate was used as an initiator, all of these are analytical grade (Sigma-Aldrich) and purity $\geq 99 \%$. The monomer used in the first experimental part was washed to remove the inhibitor, using a solution of $1 \mathrm{~N}$ sodium hydroxide and subsequently with distilled water, sodium dodecyl sulfate as surfactant (SDS).

For the synthesis of the nanoparticles zinc acetate dihydrate, sodium hydroxide was used.

\section{Synthesis of zinc oxide nanoparticles by the sol gel method}

Was prepared a solution $0.8 \%$ of dihydrate acetate in methanol and another $0.5 \mathrm{M}$ solution of sodium hydroxide in methanol were prepared. The $\mathrm{NaOH}$ solution was added dropwise in the zinc acetate solution under magnetic stirring until an approximate $\mathrm{pH}$ of 9 of the final solution was achieved. The solution was placed in a water bath at $60{ }^{\circ} \mathrm{C}$ for one hour under magnetic stirring. Once the time is up, the reaction flask is subjected to a cold bath to stop the growth. The nanoparticles were separated by centrifugation for 10 minutes at $6000 \mathrm{RPM}$ in $50 \mathrm{~mL}$ falcon tubes. At the end of the centrifugation, the ethanol is discarded, and the zinc oxide is collected in a crucible. Finally, it was dried for 12 hours at $60{ }^{\circ} \mathrm{C}$ in a convection oven.

\section{Polymerization of butilo acrylate}

Emulsion polymerization process via FRP. In a typical procedure, the reaction was carried out, using a constant volume of distilled water for the aqueous phase, with a concentration of Sodium Dodecyl Sulfate (SDS), while for the dispersed phase butyl acrylate with sodium persulfate initiator is added. The synthesis was carried out at a stirring speed of $1300 \mathrm{rpm}$ at a temperature of $70 \pm 5^{\circ} \mathrm{C}$ for 6 hours. 


\section{Polymerization of emulsion butilo acrylate with incorporation of zinc oxide nanoparticles}

Emulsion polymerization process via FRP. The reaction is carried out, using a constant volume of distilled water for the aqueous phase, with a concentration of Sodium Dodecyl Sulfate (SDS), while for the dispersed phase butyl acrylate is added with the zinc oxide nanoparticles, they are incorporated by sonication, with sodium persulfate initiator. The synthesis will take place at a stirring speed of $1300 \mathrm{rpm}$ at a temperature of $70 \pm 5^{\circ} \mathrm{C}$ for 6 hours.

\section{Characterization $\mathrm{ZnO}$}

\section{Diffraction X-ray}

Part of the structural characterization was done by X-ray diffraction, in order to corroborate that the synthesis had been carried out properly and that zinc oxide nanoparticles were effectively obtained, their level of purity, the crystalline phase obtained, as well as Crystal size calculation. The crystal size is determined using the Debye-Scherrer equation, in which it must be taken into account that the widening of the diffraction peak is caused by the size of the crystal of the sample and by the optics of the Xray instrument [5].

$t=\frac{0.9 \lambda}{B \cos \theta_{B}}$

The nanoparticles $\mathrm{ZnO}$ showed the known XRD pattern of the hexagonal phase of the wurtzite structure, which according to what is reported in the literature, The pattern which is shown in Graphic 1 of XRD showed peaks at a value of $2 \theta$ of 31.83 (100), 34.38 (002), 36.22 (101), 47.62 (102), 56.62 (110), 62.86 (103), 66.42 (200), 67.98 (112), 69.2 (201), 72.49 (), and 77.02 (022) [6].

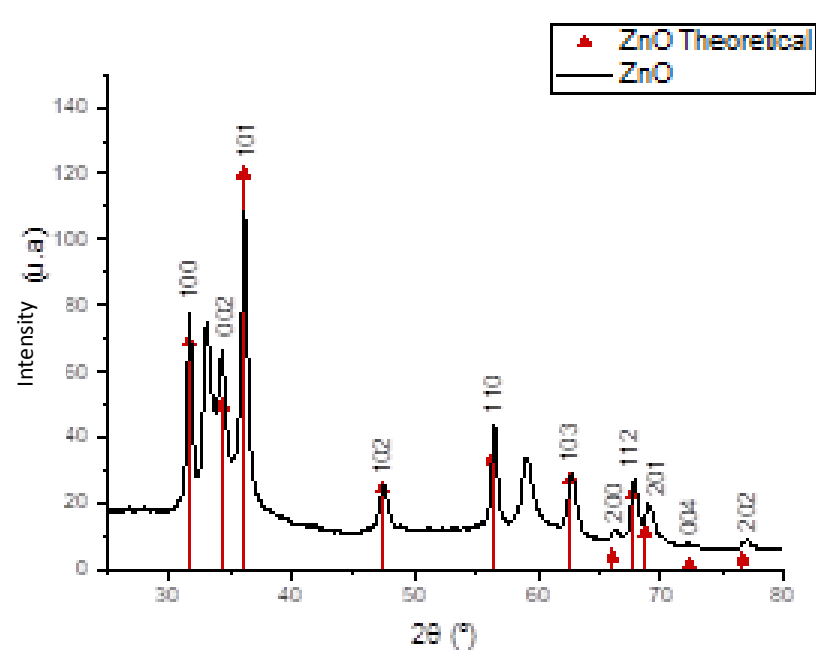

Graphic 1 Diffractogram $\mathrm{ZnO}$ synthesized via sol-gel $\mathrm{pH}$ 9

\section{Diffuse reflectance UV-Vis spectroscopy}

In order to obtain a better approximation, the diffuse reflectance UV-Vis spectroscopy technique was used and the absorption coefficient of the sample for each wavelength was estimated from the absorption spectrum and a graph of $(\alpha \hat{N} v) 2$ vs $(K v)$ for the estimation of the banned band energy according to the Kubelka-Munk model for which the following Egap value $=3.16 \mathrm{eV}$ (see Graphic 2) was obtained, the decrease in value with respect to what is reported in the literature indicates that The particle size is smaller.

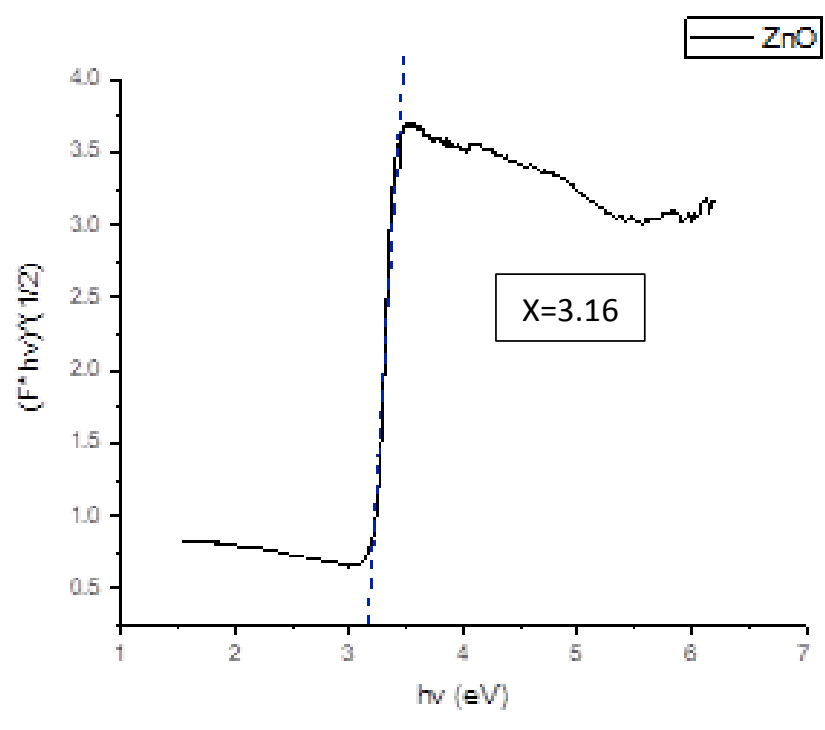

Graphic 2 Kubelka Munk graph for the ZnO sample

Forbidden band energy is influenced by several factors of nanoparticles like the morphology, particle size, composition and presence of defects (oxygen vacancies). 


\section{Infrared Spectroscopy $\mathrm{ZnO}$}

The IR spectrum for $\mathrm{ZnO}$ (see Graphic 3), is observed. The signal at $447 \mathrm{~cm}^{-1}$ is a characteristic signal of the stretching vibrations of the $\mathrm{Zn}-\mathrm{O}$ bond. The $3420 \mathrm{~cm}^{-1}$ signal belongs to the voltage vibration of the chemically unbound $\mathrm{OH}$ groups present in the sample, this because it was not completely dried and because it contains residues of the ethanol with which it was washed. The $1042 \mathrm{~cm}^{-1}$ signal belongs to a $\mathrm{C}-\mathrm{O}$ bond of a primary alcohol, in this case, ethanol.

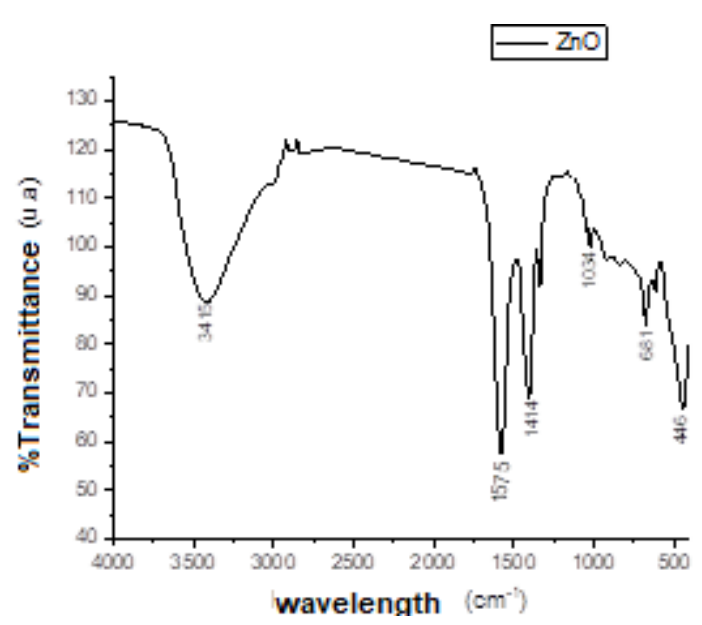

Graphic 3 Infrared spectrum on $\mathrm{KBr}$ plates for the sample $\mathrm{ZnO}$ in $\mathrm{MeOH}$

The Graphic 3 shows a peak at $446 \mathrm{~cm}^{-1}$ belonging to the link stretch band $\mathrm{Zn}-\mathrm{O}$, the 681 $\mathrm{cm}^{-1}$ peak belongs to the $\mathrm{Zn}-\mathrm{Zn}$ link and corresponds to the tetrahedral coordination of $\mathrm{Zn}$. The peaks in $1414 \mathrm{~cm}^{-1}$ and $1575 \mathrm{~cm}^{-1}$ are due to vibrations of symmetric and asymmetric stretches $\mathrm{C}=\mathrm{O}$ probably of zinc acetate precursor, for Last, the weak wide peak at $3415 \mathrm{~cm}^{-1}$ is due to $\mathrm{OH}$ stretching vibration.

The results confirmed that the $\mathrm{ZnO}$ sample obtained via sol-gel contains zinc oxide.

\section{Characterization PAB}

In order to carry out the emulsion polymerization via free radicals, it was carried out at different percentages, of which the one that gave us the best results was at $25 \%$ monomer, $1300 \mathrm{rpm}$, at a temperature of $70 \pm 2$ ${ }^{\circ} \mathrm{C}$, for $6 \mathrm{~h}$. At $10 \mathrm{~h}$ a phase separation is observed, (see Figure 1) this is due to the size of the micelles since a growth of these is observed and indicating that it can no longer be supported by the micelles generated by the surfactant.

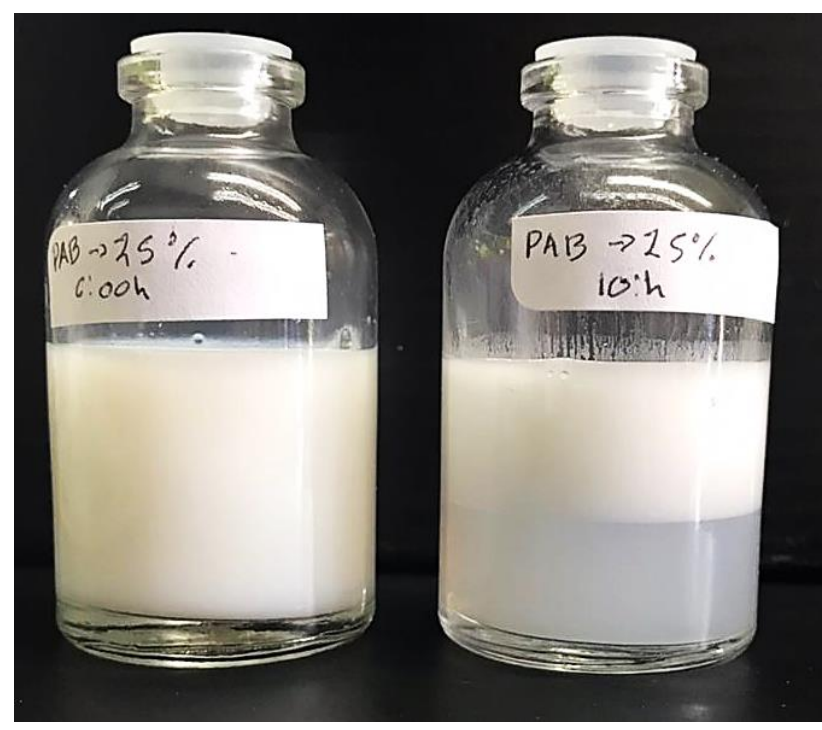

Figure 1 Emulsion at 6 and $10 \mathrm{~h}$ reaction

\section{Size of micelas at 6 and 10 hours}

By means of the dynamic light scattering technique, the measurement of the micelles was enhanced to measure the size (hydrodynamic diameter) and size distribution of the butyl polyacrylate nanospheres, it was determined by dynamic light scattering (DLS) with the equipment Nano Zetasizer Malvern, model ZEN 3600 (see Graphic 4).

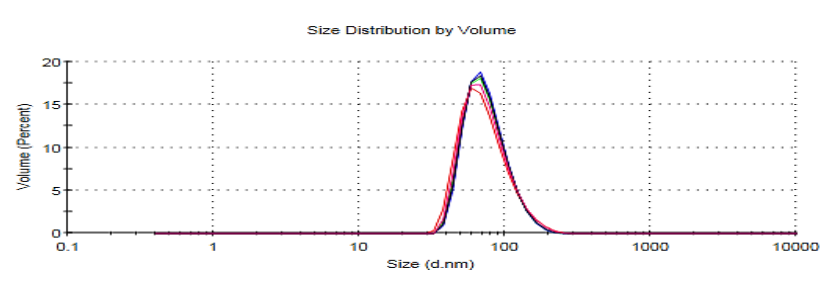

a

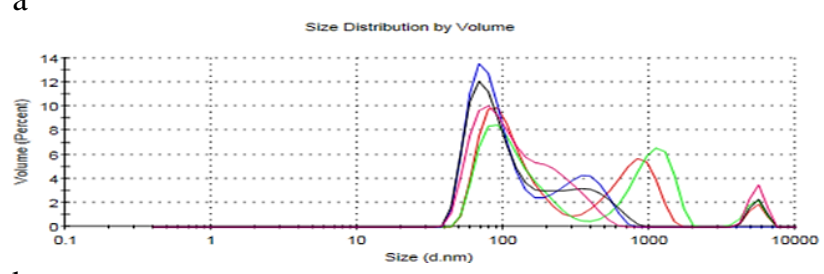

b

Graphic 4 Size of the micelles at 6:00 $\mathrm{h}$ in which the size is observed between 74 and $120 \mathrm{~nm}$. and b) micelles at 10 $\mathrm{h}$ in which a large variation in micelle size is observed

\section{Incorporation of nanoparticles to our polymer (Composite formation)}

The incorporation of the nanoparticles was made from the emulsion, it was successfully carried out since the nanoparticles were correctly distributed in the butyl polyacrylate monomer and at the same time without water insoluble. The more nanoparticles added, the greater its resemblance to a coating, as it is more transparent (see Figure 2). 


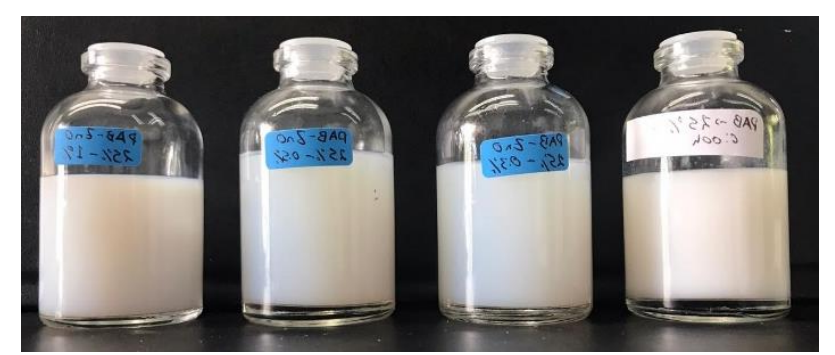

Figure 2 Incorporation of nanoparticles at $0.3 \%, 0.5 \%$ and $1 \%$

\section{UV light exposure tests}

The exposure of our compound was carried out in an FTO glass, in one, a layer of PBA was placed alone and in the other PAB with $0.3 \%$ of zinc oxide nanoparticles. We exposed it to UV light for 30 minutes, after that time it is observed that the sample that does not have nanoparticles is burned, and that which has nanoparticles has greater resistance to UV radiation (see Figure 3).

a) Before

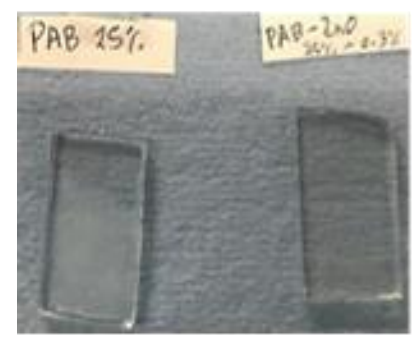

b) After

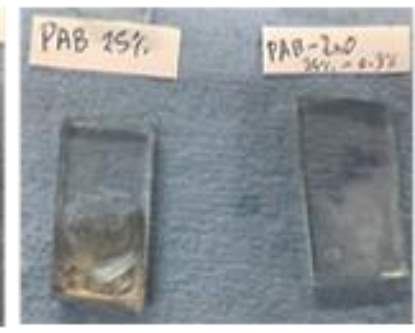

Figure 3 a) before being exposed to UV radiation. b) after being exposed to UV radiation

\section{Application of the composite in different surfaces and sun exposure}

In order to verify the influence of the nanoparticles against $U V$ radiation, 16 samples were exposed to the sun for 15 days, corresponding to each of the characteristics of the synthesis (butyl polyacrylate with different concentrations of nanoparticles- $\mathrm{ZnO}, 0.3 \%$. 0.5 $\%$ and $1 \%$ ) as well as on different surfaces (glass, wood, metal, acrylic) (see Figure 4).
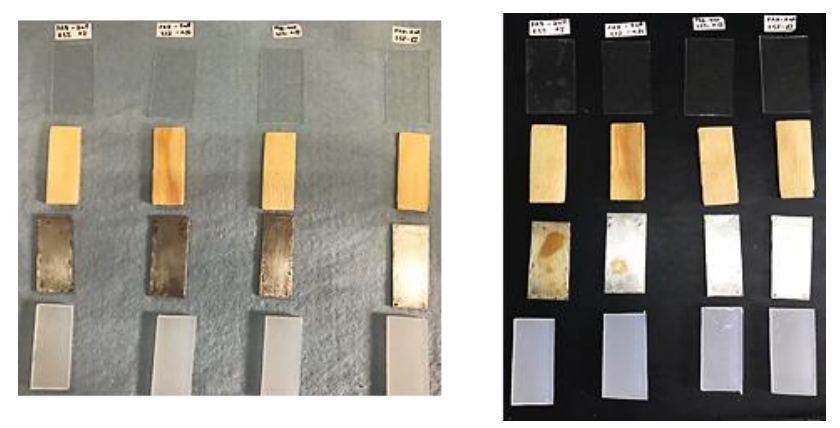

Figure 4 a) before sun exposure b) after one week in the sun
June 2020 Vol.7 No.20 7-12

In Figure 4 different surfaces are observed with polymer (PAB, PAB-Zno- $0.3 \%$, PAB-Zno- $0.5 \%$, PAB-Zno-1\%) before being exposed to the sun's radiation and in the following image after a week exposed to the sun, where it is clear that the polymer in addition to giving UV protection to the metal also makes it more resistant to corrosion.

Noting that when applying the coating it has a better adhesion in the acrylic, then in the metal, in the glass and in the wood it does not adhere, on the contrary it is observed that it is absorbed.

\section{Conclusions}

The emulsion polymerization is less aggressive to the environment due to its composition is based on water and not to aggressive reagents to the environment, and the obtaining of a greener material.

When you have nanoparticles, you get a more transparent composite, this is because the polymer only makes zones of chain accommodation and crystallizes, the nanoparticles prevent this accommodation, causing an amorphous arrangement, which does not have nanoparticles, is more opaque and whitish, affecting the hue of the surface on which it is applied.

In all cases, the coating that has the nanoparticles incorporated was found to be more resistant to exposure to UV radiation.

The polymeric coating has better adhesion on the acrylic substrate, then on the metal one, later the glass and finally on the wooden substrate. Because it is absorbed in wood.

In the metallic substrate, corrosion protection is also observed, as the concentration of nanoparticles increases, the metal retains its hue, where only the polymer is, the metal corrodes, this happens because butyl acrylate has a more acidic $\mathrm{pH}$., and as the nanoparticles are added it becomes more basic.

\section{References}

[1] Gilbert, R. G., Emulsion Polymerization: A Mechanistic Approach, Ed. Academic Press, (London), 1995, Chap. 1-2, p. 1-77.

MONTERO-GUZMAN, Erika, GALINDO, R. and FUENTES-RAMIREZ, R. Incorporation of $\mathrm{ZnO}$ nanoparticles in polymeric matrices as UV protector. Journal of Technology and Innovation. 2020 
[2] González-Blanco, R.; Cunningham, M. F.; Saldívar-Guerra, E. J. J. o. P. S. P. A. P. C., High solids TEMPO-mediated radical semibatch emulsion polymerization of styrene. 2013

[3] Yamak, H. B. Emulsion Polymerization: Effect of Polymerization Variables on theProperties of Vinyl Acetate Based Copolymer Latexes. Polymer Science: In Tech.Chap. 2013.2, p. 35-72.

[4] Nguyen, T. V.; Dao, P. H.; Duong, K. L.; Duong, Q. H.; Vu, Q. T.; Nguyen, A. H.; Le, T. L. J. P. i. O. C., Effect of R-TiO2 and $\mathrm{ZnO}$ nanoparticles on the UV-shielding efficiency of water-borne acrylic coating. 2017, 110, 114-121

[5] García, M.L.R.J., Determinación del tamaño de cristal utilizando el software Jade 6.5. 2007.

[6] Aquino, P., et al., Caracterización de nanopartículas de $\mathrm{ZnO}$ sintetizadas por el método de precipitación y su evaluación en la incorporación en pinturas esmalte. 2018. 84(1): p. 5-17. 